\title{
Theophylline Accelerates Human Granulocyte Apoptosis Not Via Phosphodiesterase Inhibition
}

\author{
Kozo Yasui, Bin Hu, Takayuki Nakazawa, Kazunaga Agematsu, and Atsushi Komiyama
}

Department of Pediatrics, Shinshu University School of Medicine, Matsumoto 390, Japan

\begin{abstract}
Theophylline, in addition to its bronchodilator effect, is reported to have an antiinflammatory action that may account for its clinical effectiveness in the reduction of inflammatory cells in the airway. In bronchial asthma, such inflammatory cytokines as GM-CSF and IL-5 are upregulated and have been proposed to cause granulocyte infiltration (neutrophils and eosinophils) in the airway by inhibition of granulocyte apoptosis. We examined the abilities of theophylline to counteract the prolongation of human granulocyte survival caused by cytokines. Theophylline was shown to shorten granulocyte survival in a dose-dependent manner. Upon incubation with a therapeutical concentration of theophylline $(0.1 \mathrm{mM} ; 18 \mu \mathrm{g} / \mathrm{ml})$, percentages of GM-CSF $(10 \mathrm{ng} / \mathrm{ml})$-induced delayed apoptosis increased from $18 \pm 2 \%$ to $38 \pm 3 \%(P<0.02)$ in neutrophils and from $21 \pm 2 \%$ to $35 \pm 2 \%$ ( $P<0.02 ; 24-\mathrm{h}$ incubation $)$ in eosinophils. The percentage of IL-5 $(5 \mathrm{ng} / \mathrm{ml})-$ induced delayed eosinophil apoptosis also increased from $22 \pm 4 \%$ to $33 \pm 2 \%$ $(P<0.05)$. In contrast, cyclic AMP (cAMP)-increasing agents (3-isobutylmethylxanthine, dibutyryl cAMP, and rolipram) inhibited granulocyte apoptosis in the control and anti-Fas antibody-treated cells. In eosinophils, the expression of $b c l-2$ protein decreased after incubation with theophylline. These findings suggest that theophylline accelerates granulocyte apoptosis, which may play an essential role in inflammation, and controls granulocyte longevity regardless of the elevation of intracellular cAMP levels. (J. Clin. Invest. 1997. 100:1677-1684.) Key words: cell death • Fas antigen $\bullet$ neutrophils $\bullet$ eosinophils $\bullet b c l-2$ protein
\end{abstract}

\section{Introduction}

Apoptosis, programmed cell death, is a physiologic suicide mechanism that maintains cellular homeostasis in a variety of tissues by removing unwanted cells (1). Accumulating evidence indicates that the Fas (APO-1; CD95)/Fas ligand system is an important cellular pathway responsible for the induction of apoptosis in diverse tissues (2-4).

Address correspondence to Kozo Yasui, M.D., Department of Pediatrics, Shinshu University School of Medicine, Asahi 3-1-1, Matsumoto 390, Japan. Phone: 81-263-37-2642; FAX: 81-263-37-3089.

Received for publication 17 January 1997 and accepted in revised form 29 May 1997

J. Clin. Invest.

(C) The American Society for Clinical Investigation, Inc.

0021-9738/97/10/1677/08 \$2.00

Volume 100, Number 7, October 1997, 1677-1684

http://www.jci.org
Granulocytes (neutrophils and eosinophils) play important roles at inflammatory sites due to bacterial or helminth infections and allergic diseases. The removal of these cells from the inflamed site inhibits tissue damage by activated granulocytes in normal nonpathogenic situations, and thus it is a critical event in the regulation of granulocyte function. Fas is expressed on the surface of mature human granulocytes and is capable of inducing rapid apoptosis, which suggests that the Fas pathway may represent a fundamental mechanism for the regulation of granulocyte apoptosis (5-7).

The unnecessary prolongation of granulocyte life and augmentation of bactericidal ability may produce toxic substances such as leukotriene and superoxide (8). GM-CSF extends the life of neutrophils and eosinophils $(9,10)$, and administration of GM-CSF is known to augment granulocyte function and cause side effects such as systemic responses, including shock, hypoxia, liver dysfunction, and respiratory distress $(11,12)$. The regulation of granulocyte apoptosis has been proposed as a key mechanism for the inhibition of inflammatory disease and tissue damage.

Theophylline, a methylxanthine derivative and nonspecific phosphodiesterase inhibitor that has bronchodilator effects, has been used in the treatment of bronchial asthma and has only recently been considered as a potential antiinflammatory agent. The inhibition of late asthmatic responses by theophylline has been demonstrated in relation to the regulation of the influx and activity of granulocytes (neutrophils and eosinophils) $(13,14)$. These effects of theophylline occur at serum concentrations within the accepted therapeutic range (14).

The present study was undertaken to evaluate the effects of theophylline on the apoptosis of granulocytes induced by anti-Fas antibody and to determine what mechanism underlies the effects in order to clarify the antiinflammatory potential of theophylline.

\section{Methods}

Reagents. Percoll and dextran T500 were purchased from Pharmacia Fine Chemicals (Uppsala, Sweden). Theophylline, dibutyryl-adenosine $3^{\prime}, 5^{\prime}$ monophosphate, 3-isobutylmethylxanthine (IBMX, ${ }^{1}$ a phosphodiesterase inhibitor), DMSO, and Hepes were purchased from Sigma Chemical Co. (St. Louis, MO). A specific phosphodiesterase IV inhibitor (Rolipram; ME3167) was a gift from Meiji Seika Kaisha (Kawasaki, Japan). Recombinant human GM-CSF (rhGMCSF) was supplied by Kirin Brewery (Tokyo, Japan) and human IL-5 was purchased from Genzyme Corp. (Cambridge, MA). IgM anti-Fas antibody (CH11), FITC-labeled anti-Fas monoclonal antibody, and FITC-labeled anti-IgG1 mAb were purchased from MBL (Nagoya, Japan). FITC-labeled anti-bcl-2 (clone 124) was from Dako Japan (Kyoto, Japan). Anti-CD16 mAb-coated immunologic magnetic beads and the magnetic cell sorter system were purchased from Miltenyi Biotec Inc. (Bergisch Gladbach, Germany).

1. Abbreviation used in this paper: IBMX, 3-isobutylmethylxanthine. 

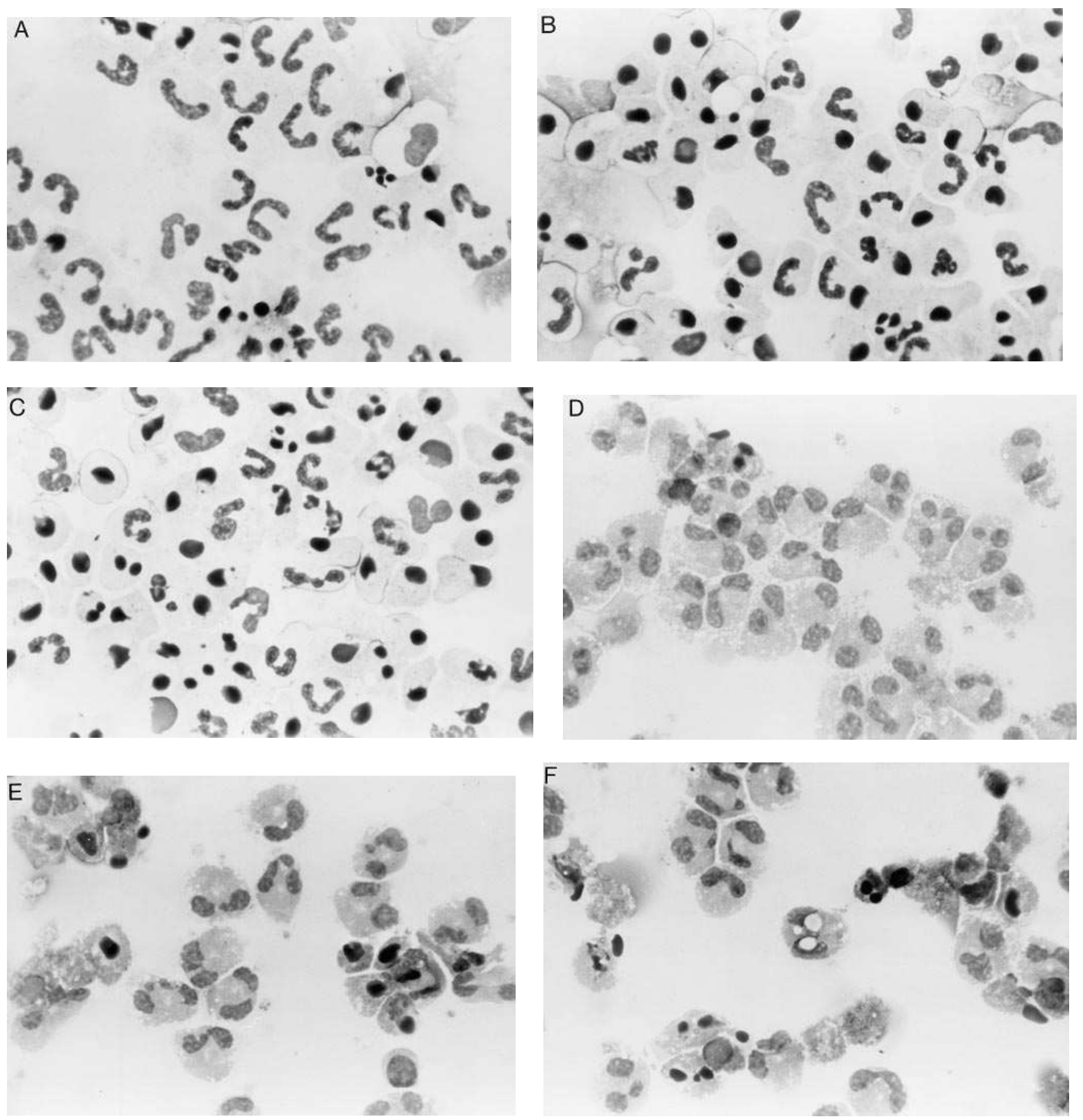

Figure 1. Morphologic features of neutrophils $(A-C)$ and eosinophils $(D-F)$ incubated with $1 \mu \mathrm{g} / \mathrm{ml} \mathrm{CH11} \mathrm{(anti-Fas} \mathrm{antibody)} \mathrm{and} \mathrm{theophylline}$ $(1 \mathrm{mM})$. May-Grünwald-Giemsa-stained preparations were photographed at 1,000×. Each granulocyte population was incubated for $9 \mathrm{~h}$ in the control experiment $(A$ and $D)$, with anti-Fas antibody $(B$ and $E$ ) or with the antibody and theophylline $(C$ and $F)$.

Preparation of cells. Heparinized venous blood was obtained from healthy volunteers. Neutrophils were isolated by dextran sedimentation and centrifugation on a Histopaque gradient (without endotoxin; Sigma Chemical Co.) as previously described (15). Contaminating red blood cells were removed by cold hypotonic water lysis. Cells were then subjected to another density cut using centrifugation over a Percoll gradient in order to isolate neutrophils from contaminating eosinophils. Eosinophils were purified from peripheral blood of slightly allergic donors (mild rhinitis), using gradient centrifugation and negative selection with anti-CD16 mAb-coated immunologic magnetic beads and a magnetic cell sorter. The purity of the isolate was assessed by preparing cytocentrifuged smears and staining with May-Grünwald-Giemsa (Merck Ltd, Darmstadt, Germany) stain. The purity of the neutrophil and eosinophil preparations was $>98 \%$, and granulocyte viability was $>99 \%$, as determined by trypan blue dye exclusion (Sigma Chemical Co.).

Assessment of apoptosis. May-Grünwald-Giemsa-stained cytospun smears were prepared from cells incubated in HBSS buffered with 10 mM HEPES, pH 7.35, without $\mathrm{Ca}^{2+}$ and $\mathrm{Mg}^{2+}$ in order to prevent clotting. The cells were incubated in the presence or absence of antiFas antibody (CH11). The percentage of apoptotic cells was determined from 500-cell counts by two observers. Apoptotic cells were 
identified by characteristic chromatin condensation, cytoplasmic vacuolization, and formation of apoptotic bodies.

DNA fragmentation. First, $2 \times 10^{6}$ cells were lysed by incubation for $15 \mathrm{~min}$ in $400 \mu \mathrm{l}$ of a cold mixture of $10 \mathrm{mM}$ Tris $\cdot \mathrm{HCl}, \mathrm{pH} 7.4,0.2$ mM EDTA, and $0.2 \%$ Triton X-100. The lysate was centrifuged for 5 $\min$ at 10,000 g. The supernatant was extracted with chloroform/ isoamyl alcohol/phenol, and the aqueous phase was collected. The DNA was precipitated with $50 \%$ 2-propranolol and $0.5 \mathrm{M}$ sodium acetate and left at $-80^{\circ} \mathrm{C}$ overnight. After digestion with $50 \mu \mathrm{g} / \mathrm{ml}$ RNase A (Boehringer Mannheim, Mannheim, Germany) for $1 \mathrm{~h}$ at $37^{\circ} \mathrm{C}$, the samples were electrophoresed through a $1.2 \%$ agarose gel and stained with $0.5 \mu \mathrm{g} / \mathrm{ml}$ ethidium bromide.

Immunofluorescence flow cytometry. To determine Fas expression, cells were incubated with FITC-labeled anti-Fas antibody for 30 min at $4^{\circ} \mathrm{C}$, washed twice with PBS and analyzed using a FACScan ${ }^{\circledR}$ (Becton Dickinson \& Co., Mountain View, CA). For detection of intracellular $b c l-2$, cells were fixed and permeabilized with Ortho Permeafix (Ortho Diagnostic Systems Inc., Raritan, NJ) for $40 \mathrm{~min}$ at room temperature. The cells were washed with $\mathrm{PBS}$ at $4^{\circ} \mathrm{C}$, followed by immediate addition of FITC-conjugated antibody and further incubation for $60 \mathrm{~min}$ at $4^{\circ} \mathrm{C}$. The cells were resuspended in ice-cold PBS at a concentration of $10^{7}$ cells $/ \mathrm{ml}$. Irrelative FITC-labeled anti$\mathrm{IgG}_{1} \mathrm{mAb}$ staining was used as the negative control.

Statistical analysis. All data are presented as means \pm SD. The significance of differences between groups was determined by Student's $t$ test. $P<0.05$ was considered significant in all cases.

\section{Results}

Anti-Fas antibody-induced apoptosis. As shown in Fig. 1, neutrophils and eosinophils were treated with or without $1 \mu \mathrm{g} / \mathrm{ml}$ of anti-Fas antibody (CH11) for the indicated times, and stained with May-Grünwald-Giemsa stain. At the light microscopic level, the treated neutrophils demonstrated the characteristic morphology of apoptosis (Fig. $1 \mathrm{~B}$, neutrophils with CH11 for 9 h; Fig. $1 E$, eosinophils with $\mathrm{CH} 11$ for $24 \mathrm{~h}$ ): one or a few darkly stained pyknotic nuclei, compacted but structurally intact cytoplasmic organelles, and cytoplasm vacuolation were typical compared with the controls (Fig. 1, $A$ and $D$ ). Fig. 2 shows that the mean percentage of apoptotic cells with $\mathrm{CH} 11$ were $80 \pm 4 \%$ of the neutrophils vs. $26 \pm 6 \%$ of the control population ( $n=4 ; P<0.01 ; 9$-h incubation) and $46 \pm 2 \%$ of the eosinophils vs. $24 \pm 3 \%$ of the control population $(n=4 ; P<$ 0.01; 24-h incubation). Thus, apoptosis was induced in both granulocyte populations due to the treatment with anti-Fas antibody.

Effects of theophylline, IBMX, rolipram, and dibutyryl cyclic AMP on granulocyte apoptosis. Theophylline, IBMX, rolipram, and dibutyryl cyclic AMP (cAMP) were diluted in dimethyl sulfoxide and stored at $-20^{\circ} \mathrm{C}$. The cells were exposed to no more than $0.1 \%$ dimethyl sulfoxide. As shown in Fig. 3, granulocytes were cocultured with theophylline, IBMX, rolipram, or dibutyryl cAMP at various concentrations. At the time intervals, the proportion of apoptotic cells was assessed morphologically. The addition of IBMX, rolipram (specific phosphodiesterase inhibitors), or dibutyryl cAMP to the granulocytes resulted in a concentration-dependent inhibition of granulocyte apoptosis. Specially, upon addition of $1 \mathrm{mM}$ IBMX, the percentage of apoptotic cells in the control neutrophil and eosinophil populations was reduced from $24 \pm 2$ to $6 \pm 2 \%$ ( $P<$ $0.01 ; n=4)$ and from $21 \pm 2 \%$ to $12 \pm 1 \%(P<0.02 ; n=4)$, respectively. Under the same conditions, the percentage of apoptotic cells in the $\mathrm{CH} 11$-treated neutrophil and eosinophil was also reduced from $78 \pm 2 \%$ to $32 \pm 3 \%(P<0.01 ; n=4)$ and

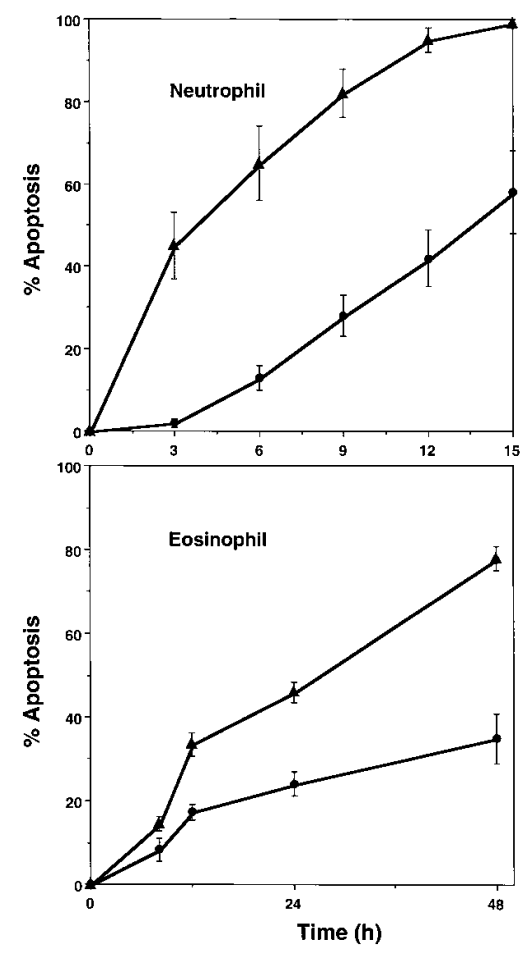

Figure 2. Timedependent induction of apoptotic granulocytes (assessed morphologically). Cells were treated for various time periods with $(\mathbf{\Delta})$ or without $(\bullet)$ $1 \mu \mathrm{g} / \mathrm{ml}$ anti-Fas antibody. Percentages of apoptotic cells were estimated on May-Grünwald-Giemsa-stained cytospun preparations. Data represent the mean $\pm \mathrm{SD}$ of four separate determinations.

from $47 \pm 3 \%$ to $21 \pm 2 \%(P<0.02 ; n=4)$, respectively. The addition of rolipram or dibutyryl cAMP also significantly reduced the percentage of apoptotic cells in both granulocyte populations $(P<0.05)$. In contrast, theophylline caused significant induction of apoptosis of both cell types upon addition of $1 \mathrm{mM}$ theophylline, the percentage of apoptotic cells in the control neutrophil (Fig. $3 A$ ) and eosinophil (Fig. $3 B$ ) populations increased to $38 \pm 4 \%(P<0.02 ; n=4)$ and $30 \pm 2 \%(P<$ $0.02 ; n=4)$, respectively. The percentage of apoptotic cells in the $\mathrm{CH} 11$-treated neutrophil and eosinophil populations also increased, to $90 \pm 3 \%(P<0.01 ; n=4)$ and $58 \pm 2 \%(P<0.05$; $n=4)$, respectively. The morphological results are shown in Fig. $1, C$ and $F$. At a therapeutic concentration $(0.1 \mathrm{mM})$, the percentage of apoptotic cells significantly increased in the control neutrophils and eosinophils (Fig. 3, $A$ and $B$ ).

Cellular apoptosis induced by anti-Fas antibody was confirmed by electrophoresis (Fig. 4). Agarose gel electrophoresis of DNA from the granulocytes showed characteristic ladderlike apoptotic patterns (DNA degradation). The augmentation of laddering of DNA extracts by theophylline, and the inhibition by IBMX and dibutyryl cAMP is clearly visible in Fig. 4.

Effects of theophylline on GM-CSF- or IL-5-induced delayed granulocyte apoptosis. When neutrophils and eosinophils were incubated with GM-CSF $(10 \mathrm{ng} / \mathrm{ml} ; 45 \mathrm{pM})$, the percentage of apoptotic cells dramatically decreased. After incubation for $9 \mathrm{~h}$ with $\mathrm{CH} 11(1 \mu \mathrm{g} / \mathrm{ml})$, approximately $80 \%$ of the neutrophils exhibited apoptotic characteristics. GM-CSF markedly prevented anti-Fas antibody-induced neutrophil apoptosis (from 78 to $18 \%$; Fig. 5). When eosinophils were incubated for $24 \mathrm{~h}$, GM-CSF or IL-5 (5 ng/ml) inhibited CH11-induced eosinophil apoptosis (from 47 to 21 or $22 \%$; Fig. 5) after the interval. Theophylline resulted in a concentration-dependent increase in granulocyte apoptosis. Upon addition of a therapeutical concentration of theophylline ( 0.1 

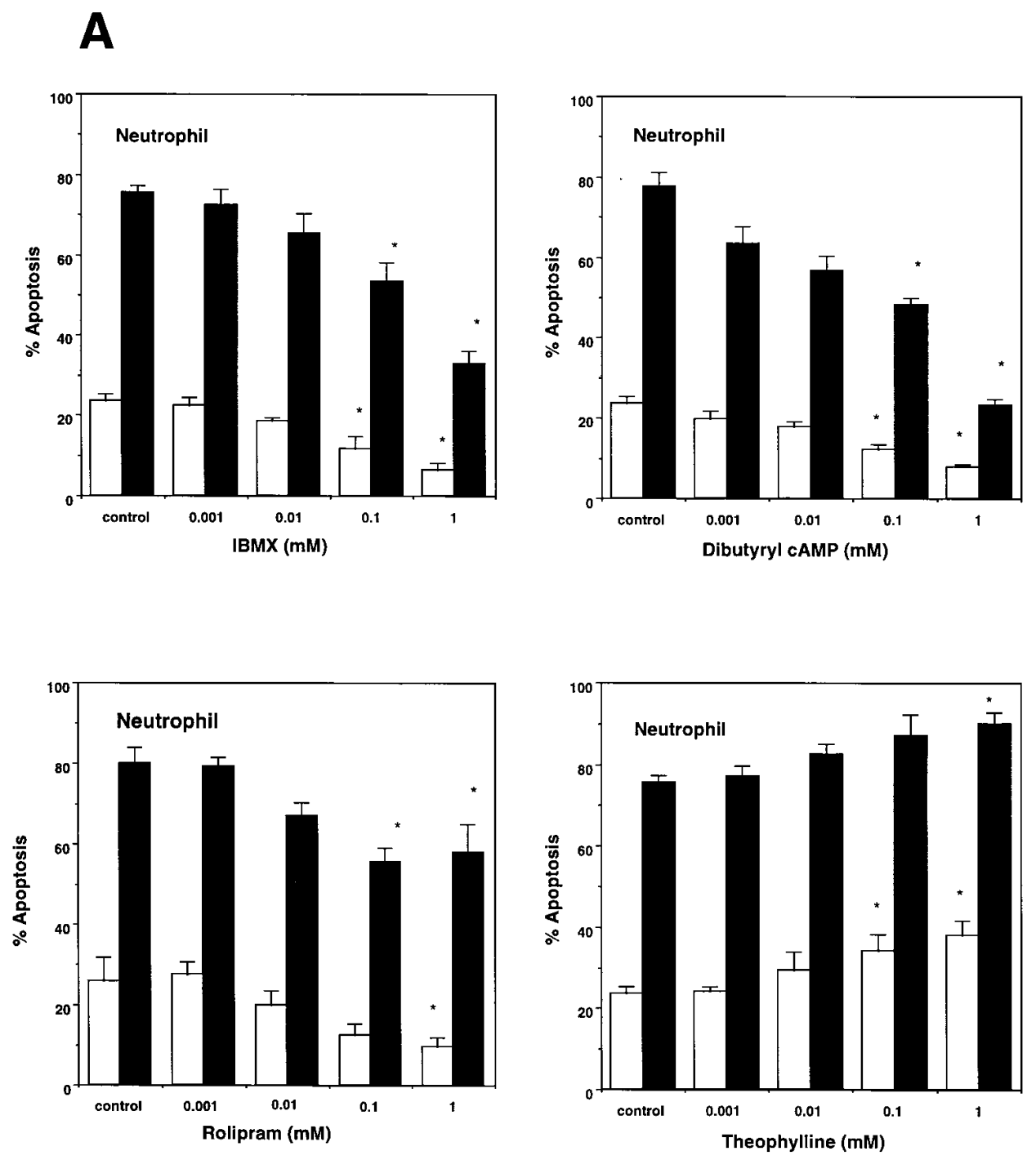

Figure 3. Effect of IBMX, rolipram, dibutyryl cAMP, and theophylline on granulocyte apoptosis. Neutrophils $(A)$ were incubated for $9 \mathrm{~h}$ and eosinophils $(B)$ for $24 \mathrm{~h}$, and percentages of apoptotic cells were estimated morphologically. Dark columns represent data of cells treated with $1 \mu \mathrm{g} / \mathrm{ml} \mathrm{CH} 11$ (anti-Fas antibody) and open columns represent data of nontreated cells. Data represent the mean \pm SD of four separate determinations. $* P<0.05$ compared with no stimulus controls by $t$ test.

$\mathrm{mM} ; 18 \mu \mathrm{g} / \mathrm{ml})$, the percentage of apoptotic cells significantly increased from $18 \pm 2 \%$ to $38 \pm 3 \%(n=4, P<0.02)$ in the neutrophils and from $21 \pm 2 \%$ to $35 \pm 2 \%(n=4, P<0.02)$ in the eosinophils incubated with GM-CSF. Theophylline $(0.1 \mathrm{mM})$ also increased the percentage of the apoptotic eosinophils incubated with IL-5 from $22 \pm 4 \%$ to $33 \pm 2 \%(n=4, P<0.05)$.

Granulocytes were treated with theophylline $(0.05 \mathrm{mM} ; 9$ $\mu \mathrm{g} / \mathrm{ml})$ at $37^{\circ} \mathrm{C}$ for various time periods in the presence of GMCSF (10 ng/ml) (Fig. 6). Long incubation periods with theophylline at the lower concentration significantly reduced the viability of both neutrophils and eosinophils.

Surface expression of Fas. Cell surface expression of Fas was detected on the control neutrophils by direct immunofluorescence flow cytometry using FITC-conjugated mAb (Fig. 7). Mean fluorescence intensity did not change after incubation with $1 \mathrm{mM}$ IBMX, dibutyryl cAMP, or theophylline for $8 \mathrm{~h}$.

Because $b c l$-2 expression is known to counteract apoptosis, flow cytometry was used to analyze the expression of $b c l-2$ protein by eosinophils. Fig. 8 shows that theophylline $(0.1 \mathrm{mM})$ reduced the expression of $b c l-2$ by eosinophils incubated for $72 \mathrm{~h}$ in HBSS.

\section{Discussion}

Human neutrophils and eosinophils are known to play crucial roles at inflammatory sites. An abundance of evidence has established the key regulatory role of these cells in inflammation and host immune responses. Several inflammatory cytokines including GM-CSF, IL-3, and IL-5 are reported to support the survival and the activation of these cells (16-18). Fas antigen or apoptosis antigen-1 (APO-1; CD95), a member of the tumor necrosis factor/nerve growth factor receptor family, is capable of inducing apoptosis in susceptible cell populations (2, 3 ). The finding that human peripheral blood neutrophils and eosinophils express functional Fas antigen suggests that this molecule may also be involved in the regulation of inflammatory disease $(5-7,19)$. The Fas-Fas ligand system in vivo is recognized as a mechanism to remove unwanted cells in the human body $(2,3,19)$. Therefore, we hypothesized that a variety of inflammatory cytokines (GM-CSF, IL-3, IL-5) augment granulocyte development and survival (= inflammation) and that the Fas-Fas ligand system inhibits and regulates these cell populations. 


\section{B}
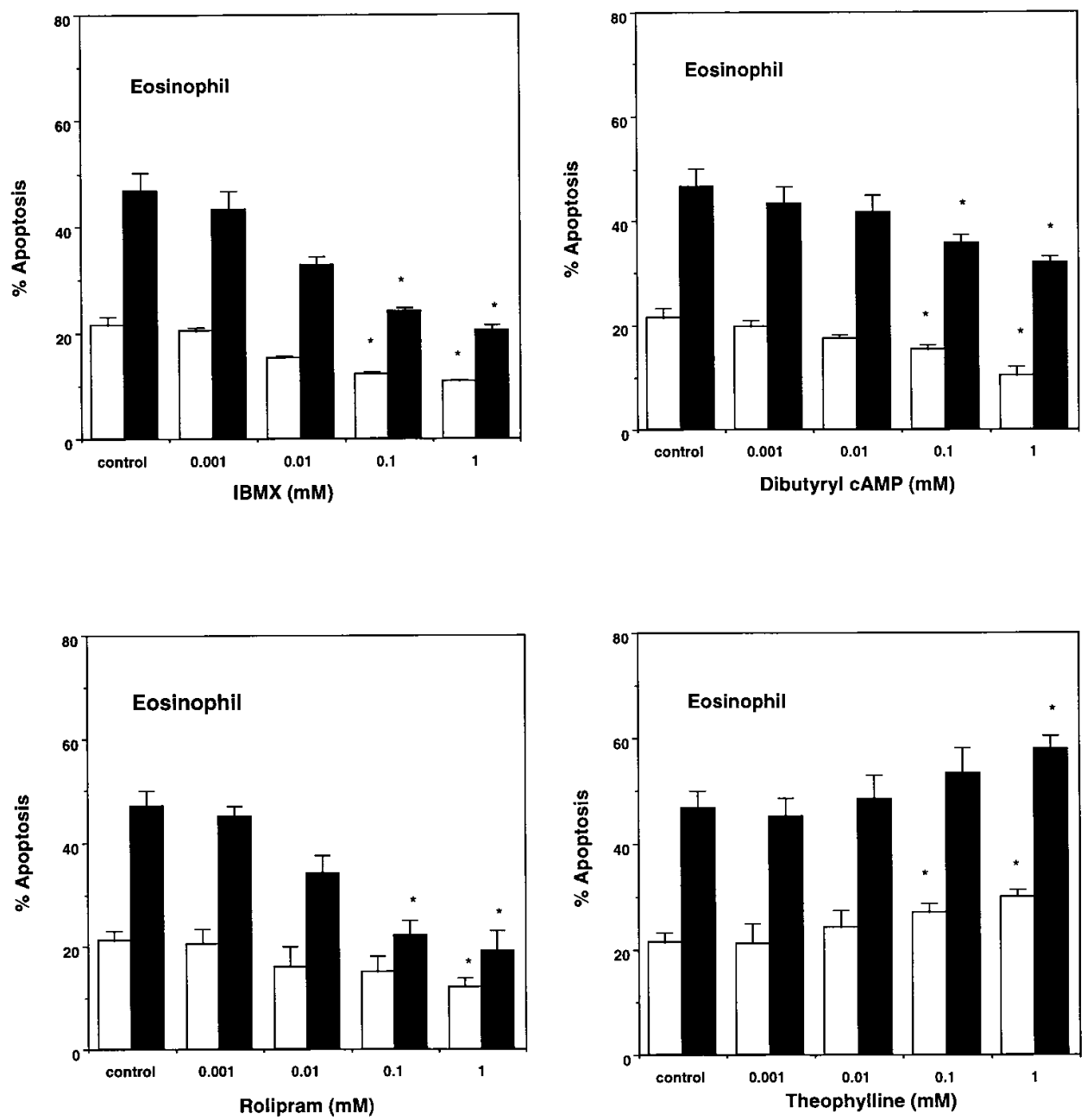

Figure 3 (Continued)

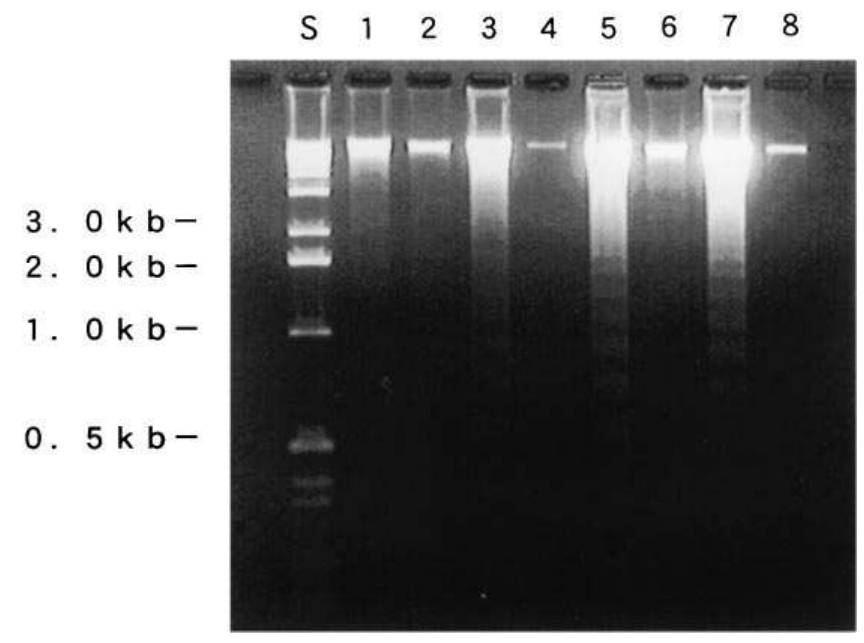

Figure 4. Agarose gel electrophoresis of DNA extracted from neutrophils after culture for $9 \mathrm{~h}$ under various conditions: (lane $S$ ) molecular weight markers, (lane 1) control neutrophils, (lane 2) neutrophils with $1 \mathrm{mM}$ IBMX, (lane 3) neutrophils with $1 \mathrm{mM}$ theophylline, (lane 4) neutrophils with $1 \mathrm{mM}$ dibutyryl cAMP, (lane 5) neutrophils with 1 $\mu \mathrm{g} / \mathrm{ml}$ anti-Fas $\mathrm{Ab}$, (lane 6) neutrophils with $\mathrm{Ab}$ and $1 \mathrm{mM}$ IBMX,
Theophylline has been used worldwide for the treatment of bronchial asthma $(20,21)$ and is currently being reevaluated as an antiinflammatory agent. Persistent inflammation in the airways is thought to be an essential feature of chronic asthma. Inflammatory cell infiltrate exists in the airway walls even in mild asthma. Theophylline is known to inhibit the activity of immunocompetent cells (22). Furthermore, bronchoscopic studies have revealed that oral theophylline therapy prevents the late asthmatic reaction and causes significant reduction in the number of granulocytes in the airway $(14,23)$. This phenomenon may be regulated by apoptosis. The findings of the present study show that, in vitro, theophylline significantly shortened granulocyte survival in a dose-dependent manner by accelerating apoptosis. Theophylline accelerated not only Fas antibody-induced granulocyte apoptosis, but also the cells' death without treatment with the antibody. In both neutrophils and eosinophils, these effects were not significant when

(lane 7) neutrophils with $\mathrm{Ab}$ and $1 \mathrm{mM}$ theophylline, (lane 8 ) neutrophils with $\mathrm{Ab}$ and $1 \mathrm{mM}$ dibutyryl cAMP. Representative data is shown. 

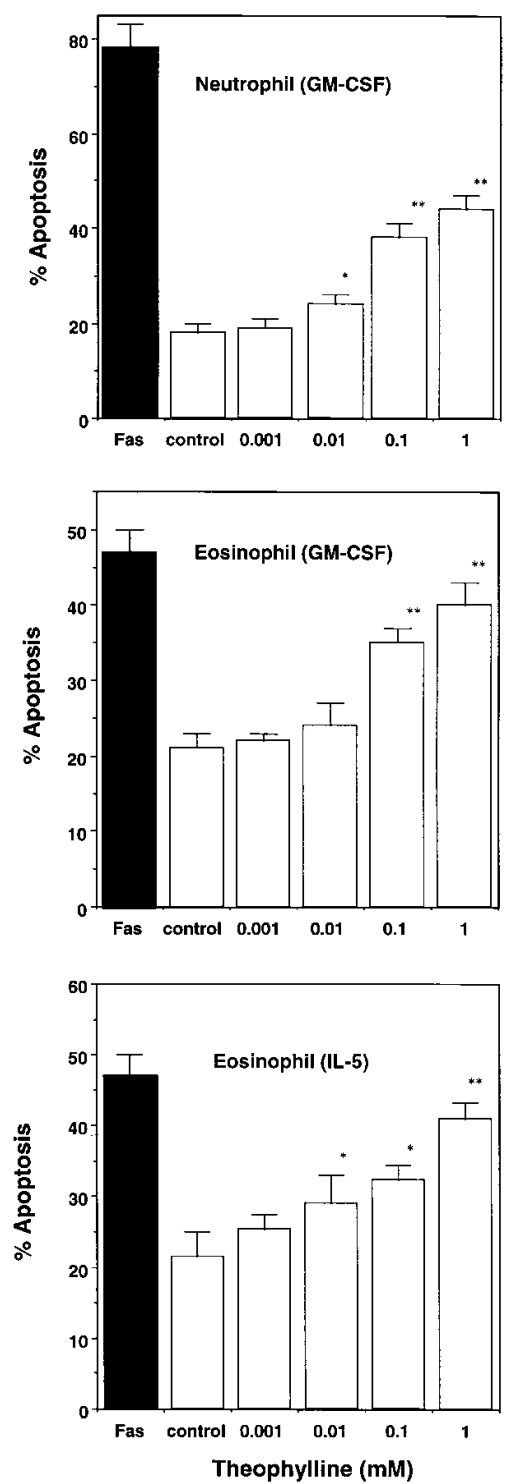

Figure 5. Effects of theophylline on GMCSF- or IL-5-induced delayed apoptosis of granulocytes. Neutrophils were incubated with GM-CSF (10 ng/ $\mathrm{ml})$ and $\mathrm{CH} 11(1 \mu \mathrm{g} / \mathrm{ml})$ for $9 \mathrm{~h}$, and eosinophils were incubated with GM-CSF or IL-5 (5 ng/ $\mathrm{ml}$ ) and $\mathrm{CH} 11$ for $24 \mathrm{~h}$. Dark columns represent data without GM-CSF or IL-5, open columns represent data with GM-CSF or IL-5.

Values represent the mean \pm SD of four separate determinations. $* P<0.05$ and $* * P<$ 0.02 compared with no theophylline controls by $t$ test.

therapeutic levels of theophylline were used. However, theophylline significantly prevented GM-CSF-mediated prolonged survival of both neutrophils and eosinophils at therapeutical level $(0.1 \mathrm{mM})$. Furthermore, theophylline inhibited IL-5mediated eosinophil survival. These effects were observed at a lower theophylline concentration $(0.05 \mathrm{mM} ; 9 \mu \mathrm{g} / \mathrm{ml})$ for longer periods of incubation. Thus, the acceleration of granulocyte apoptosis by theophylline seems to be associated with the inhibition of inflammation in the human body.

One possible explanation of the mechanism of antiinflammatory effect of theophylline is outlined below. Theophylline is known to inhibit the activation of neutrophils and eosinophils. This agent inhibits the superoxide production induced by a chemoattractant (24). cAMP-elevating agents (IBMX, forskolin, dibutyryl cAMP) and theophylline modulate chemoattractant-induced phosphatidyl inositol 3-kinase, phospholipase $\mathrm{D}$ activation, and inhibit granulocyte functions (25-27). Theophylline works as a cAMP-increasing agent (a phosphodiesterase inhibitor) in this phenomenon $(24,26)$. Cyclic AMP

alters the microfilament components of the actin cytoskeleton (28) and influences the phosphorylation of Rap protein required for the activation of NADPH oxidase (29). This inhibitory effect of theophylline on superoxide production by granulocytes was believed to be antiinflammatory $(30,31)$.

In contrast, the effect of theophylline on granulocyte apoptosis is quite different from that of other cAMP-increasing agents (IBMX, rolipram, and dibutyryl cAMP). As determined in the present study, IBMX, rolipram (specific phosphodiesterase inhibitors), and dibutyryl cAMP delayed granulocyte apoptosis in the control and anti-Fas antibody-treated cells, whereas theophylline accelerated granulocyte apoptosis. This is consistent with previous observations (32). Pentoxifylline, a methylxanthine derivative, is known to modulate neutrophil functions (33) and has been recently reported to inhibit neutrophil apoptosis (34). Theophylline's effect on granulocyte apoptosis is quite different from that of other xanthine derivatives.

Theophylline had no effect on cell surface Fas expression. $B c l-2$ is known to be an important gene involved in suppression of apoptosis, and overexpression of $b c l-2$ protein has been found to protect cells against several apoptotic stimuli (35). Mentz et al. (36) recently reported that theophylline can induce apoptosis in malignant B cells, and the drug downregulates the expression of $b c l-2$ protein. The results of the present study indicate that theophylline downregulates the expression of $b c l-2$ protein in eosinophils and may induce apoptosis. As neutrophils are essentially absent of bcl-2 expression (5) and many genes and proteins are involved in the induction or suppression of apoptosis, this notion cannot be proven beyond doubt. However, our results provide evidence that theophylline accelerates human eosinophil apoptosis, at least in part, by suppression of $b c l-2$ protein.

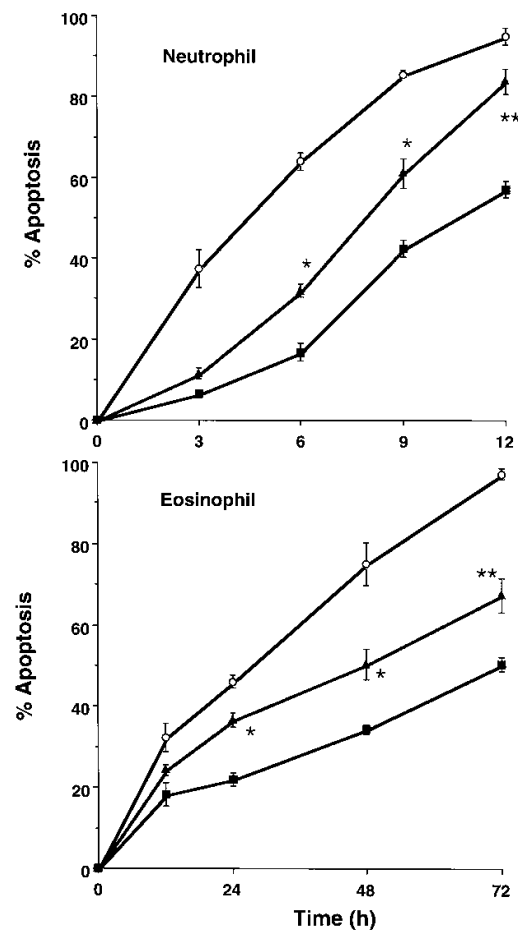

Figure 6. Time-dependent induction of apoptotic granulocytes. Cells were treated for various time periods with $1 \mu \mathrm{g} / \mathrm{ml}$ anti-Fas antibody. Cells were incubated with $(\boldsymbol{\Lambda}$ and 口) or without $(O)$ GM-CSF (10 ng/ml). Effects of theophylline $(0.05 \mathrm{mM} ; 9 \mu \mathrm{g} / \mathrm{ml})$ were also determined $(\boldsymbol{\Delta})$. Values represent the mean \pm SD of three separate determinations. $* P<0.05$ and $* * P<0.02$ compared with no theophylline controls by $t$ test. 

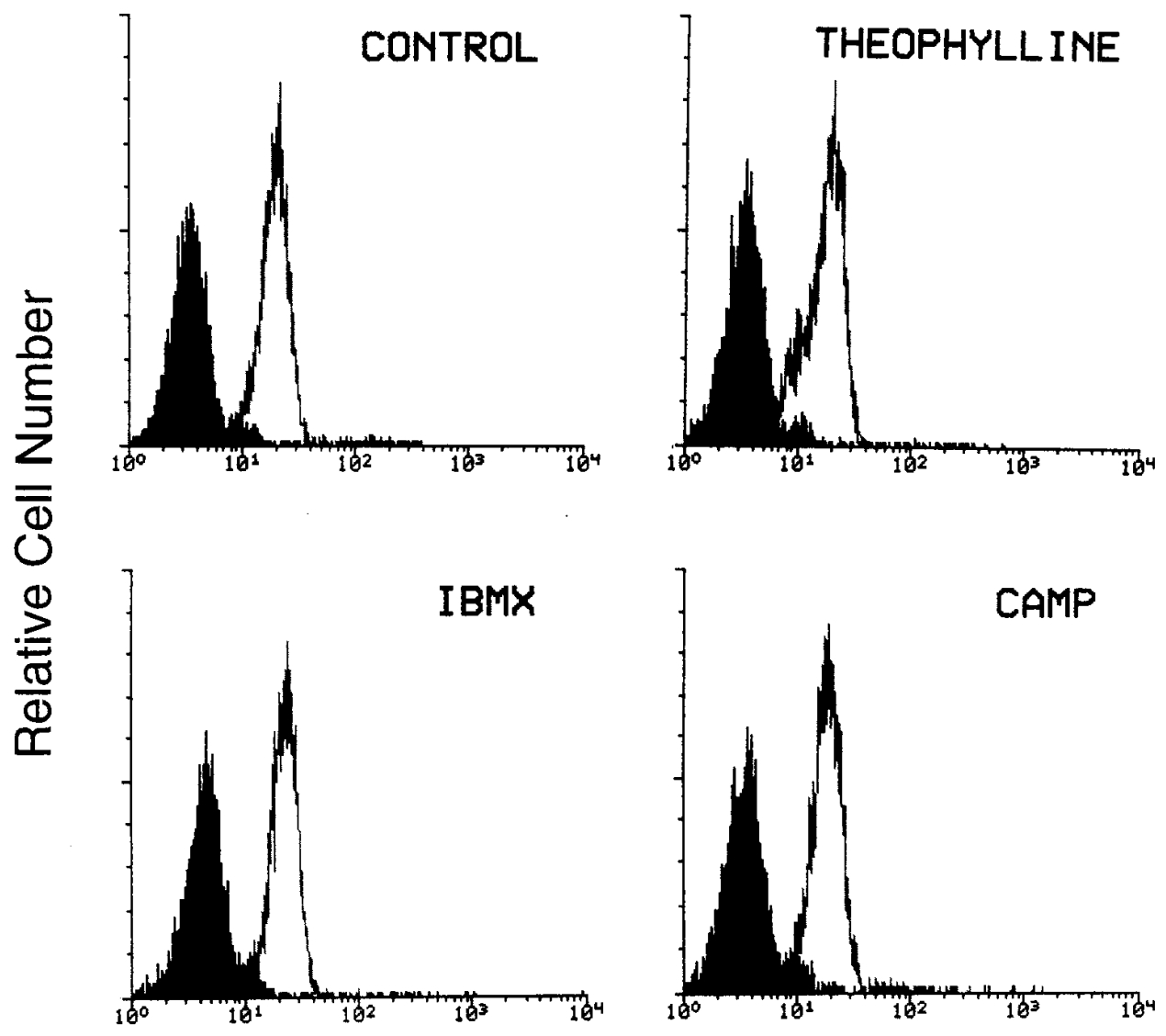

Figure 7. Cell-surface expression of Fas on human neutrophils. Direct immunofluorescence flow cytometry was performed to detect cell surface Fas expression on neutrophils. Cells were preincubated with or without agents $(1 \mathrm{mM})$ for $8 \mathrm{~h}$. Data are expressed in the form of histogram overlay depicting specific Fas staining (blank space) vs. negative control staining (solid space). RepFluorescence Intensity resentative data is shown.

\section{Acknowledgments}

This work was supported in part by grants-in-aid from the Japanese Ministry of Education, Culture and Science (07670852) and from the Japanese Ministry of Health and Welfare.

\section{References}

1. Wyllie, A.H., J.F.R. Kerr, and A.R. Currie. 1980. Cell death: the significance of apoptosis. Int. Rev. Cytol. 68:251-306.

2. Itoh, N., S. Yonehara, A. Ishii, M. Yonehara, S.-I. Mizushima, M. Sameshima, A. Hase, Y. Seto, and S. Nagata. 1991. The polypeptide encoded by the cDNA for human cell surface antigen Fas can mediate apoptosis. Cell. 66: 233-243.

3. Oehm, A., I. Behrmann, W. Falk, M. Pawlita, G. Manier, C. Klas, M. LinWeber, S. Richards, J. Dhein, B.C. Trauth, et al. 1992. Purification and molecular cloning of the APO-1 cell surface antigen, a member of the tumor necrosis factor/nerve growth factor receptor superfamily. J. Biol. Chem. 267:1070910715 .

4. Debatin, K.M., C.K. Goldman, T.A. Waldmann, and P.H. Krammer. 1993. APO-1-induced apoptosis of leukemia cells from patients with adult T-cell leukemia. Blood. 81:2972-2977.

5. Iwai, K. T. Miyawaki, T. Takizawa, A. Konno, K. Ohta, A. Yachie, H. Seki, and N. Taniguchi. 1994. Differential expression of bcl-2 and susceptibility to anti-Fas-mediated cell death in peripheral blood lymphocytes, monocytes, and neutrophils. Blood. 84:1201-1208.

6. Matsumoto, K., R.P. Schleimer, H. Saito, Y. Iikura, and B.S. Bochner. 1995. Induction of apoptosis in human eosinophils by anti-Fas antibody treatment in vitro. Blood. 86:1437-1443.

7. Druilhe, A., Z. Cai, S. Haile, S. Chouaib, and M. Pretolani. 1996. Fasmediated apoptosis in cultured human eosinophils. Blood. 87:2822-2830.

8. Rothenberg, M.E., W.F. Owen, Jr., D.S. Silberstein, J. Woods, R.J. Soberman, K.F. Austen, and R.L. Stevens. 1988. Human eosinophils have pro- longed survival, enhanced functional properties, and become hypodense when exposed to human interleukin 3. J. Clin. Invest. 81:1986-1992.

9. Lopez, A.F., D.J. Williamson, J.R. Gamble, C.G. Begley, J.M. Harlan, S.J. Klebanoff, A. Waltersdorph, G. Wong, S.C. Clark, and M.A. Vadas. 1986 Recombinant human granulocyte-macrophage colony-stimulating factor stimulates in vitro mature human neutrophil and eosinophil function, surface receptor expression, and survival. J. Clin. Invest. 78:1220-1228.

10. Tai, P.C., and C.J. Spry. 1990. The effects of recombinant granulocytemacrophage colony-stimulating factor (GM-CSF) and interleukin-3 on the secretory capacity of human blood eosinophils. Clin. Exp. Immunol. 80:426-434.

11. Verhoef, G., and M. Boogaerts. 1991. Treatment with granulocyte-macrophage colony-stimulating factor and the adult respiratory distress syndrome. Am. J. Hematol. 36:285-287.

12. Tiegs, G., J. Barsig, B. Matiba, S. Uhlig, and A. Wendel. 1994. Potentiation by granulocyte macrophage colony-stimulating factor of lipopolysaccharide toxicity in mice. J. Clin. Invest. 93:2616-2622.

13. Djukanovic, R., J.P. Finnerty, C. Lee, S. Wilson, J. Madden, and S.T. Holgate. 1995. The effects of theophylline on mucosal inflammation in asthmatic airways: biopsy results. Eur. Respir. J. 8:831-833.

14. Sullivan, P., S. Bekir, Z. Jaffar, C. Page, P. Jeffery, and J. Costello. 1994. Anti-inflammatory effects of low-dose oral theophylline in atopic asthma. Lancet. 343:1006-1008.

15. Yasui, K., M. Yamazaki, M. Miyabayashi, T. Tsuno, and A. Komiyama. 1994. Signal transduction pathway in human polymorphonuclear leukocytes for chemotaxis induced by a chemotactic factor. J. Immunol. 152:5922-5927.

16. Her, E., J. Frazer, K.F. Austen, and W.F. Owen. 1991. Eosinophil hematopoietins antagonize the programmed cell death of eosinophils-cytokine and glucocorticoid effects on eosinophils maintained by endothelial cell conditioned medium. J. Clin. Invest. 88:1982-1987.

17. Tai, P.C., L. Sun, and C.J. Spry. 1991. Effects of IL-5, granulocyte/macrophage colony-stimulating factor (GM-CSF) and IL-3 on the survival of human blood eosinophils in vitro. Clin. Exp. Immunol. 85:312-316.

18. Stern, M., L. Meagher, J. Savill, and C. Haslett. 1992. Apoptosis in human eosinophils. Programmed cell death in the eosinophil leads to phagocytosis by macrophages and is modulated by IL-5. J. Immunol. 148:3543-3549.

19. Liles, W.C., and S.J. Klebanoff. 1995. Regulation of apoptosis in neutro- 

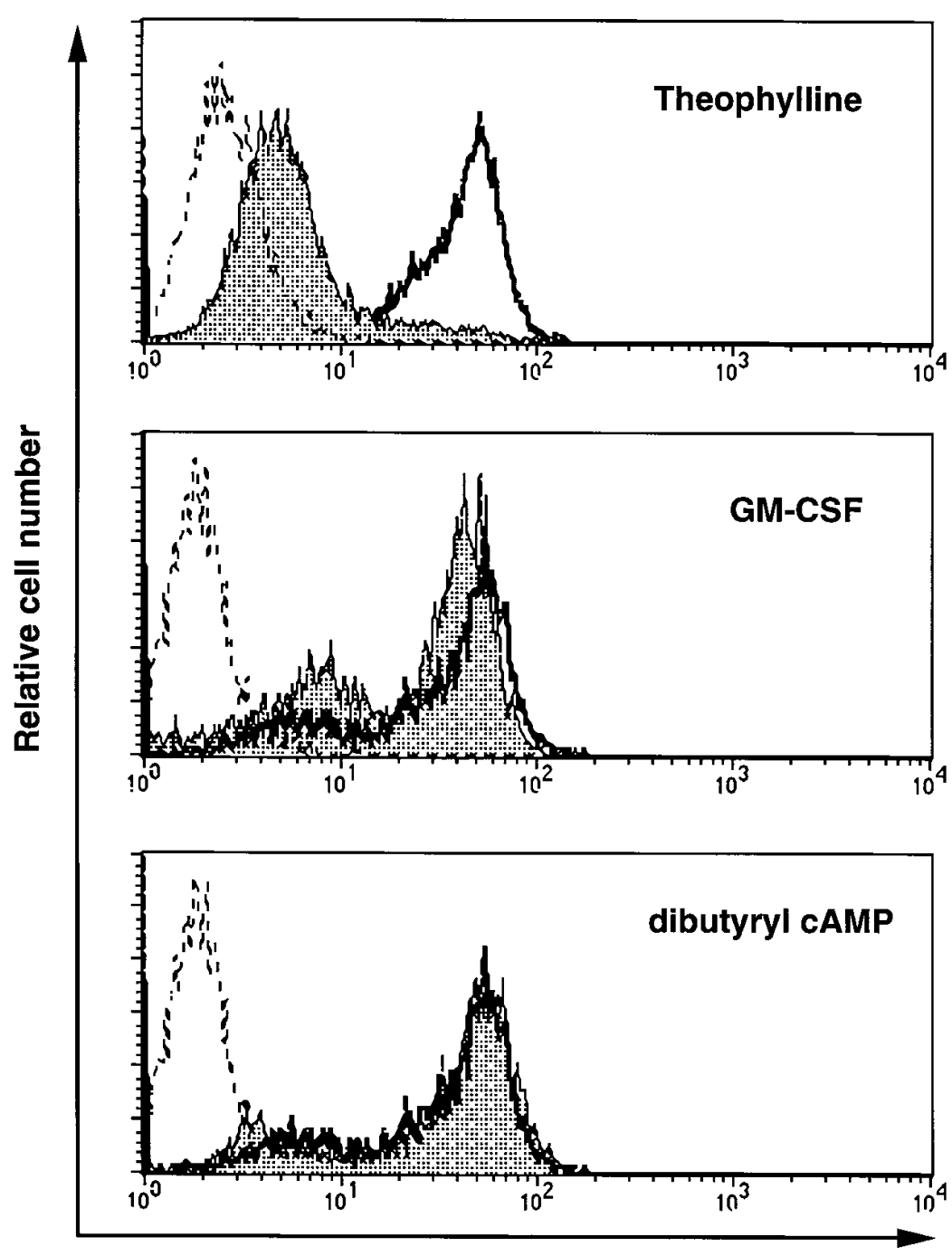

Bcl-2 (log fluorescence intensity)
Figure 8. Bcl-2 expression of eosinophils incubated in HBSS for $72 \mathrm{~h}$ (hatched area). Isotype-matched negative control $\mathrm{mAb}$ is indicated by dotted line. Cells were incubated with theophylline $(0.1 \mathrm{mM})$, GM-CSF (10 ng/ml), or dibutyryl cAMP (1 mM). Data of control cells incubated in HBSS are indicated by bold line. Representative data is shown.
phils-Fas track to death? J. Immunol. 155:3289-3291.

20. Weinberger, M. 1984. The pharmacology and therapeutic use of theophylline. J. Allergy Clin. Immunol. 73:525-540.

21. Pauwels, R. 1989. New aspects of the therapeutic potential of theophylline in asthma. J. Allergy Clin. Immunol. 83:548-553.

22. Calhoun, W.J., C.A. Stevens, and S.B. Lambert. 1991. Modulation of superoxide production of alveolar macrophages and peripheral blood mononuclear cells by beta-agonists and theophylline. J. Lab. Clin. Med. 117:514-522.

23. Crescioli, S., A. Spinazzi, M. Plebani, M. Pozzani, C.E. Mapp, P. Boschetto, and L.M. Fabbri. 1991. Theophylline inhibits early and late asthmatic reactions induced by allergens in asthmatic subjects. Ann. Allergy. 66: 245-251.

24. Nielson, C.P., J.J. Crawley, M.E. Morgan, and R.E. Vestal. 1988. Polymorphonuclear leukocyte inhibition by therapeutic concentrations of theophylline is mediated by cyclic $3^{\prime}, 5^{\prime}$ adenosine monophosphate. Am. Rev. Respir. Dis. 137:25-30.

25. Bryant, R.E., and M.C. Sutcliffe. 1974. The effect of 3',5' cyclic adenosine monophosphate on granulocyte adhesion. J. Clin. Invest. 54:1241-1244.

26. Tyagi, S.R., S.C. Olson, D.N. Burnham, and J.D. Lambeth. 1991. Cyclic AMP-elevating agents block chemoattractant activation of diradylglycerol generation by inhibiting phospholipase D activation. J. Biol. Chem. 266:3498-3504.

27. Ahmed, M.U., K. Hazeki, O. Hazeki, T. Katada, and M. Ui. 1995. Cyclic AMP-increasing agents interfere with chemoattractant-induced respiratory burst in neutrophils as a result of the inhibition of phosphatidylinositol 3-kinase rather than receptor-operated $\mathrm{Ca}^{2+}$ influx. J. Biol. Chem. 270:23816-23822.

28. Downey, G.P., E.L. Elson, B. Schwab, S.C. Erzurum, S.K. Young, and G.S. Worthen. 1991. Biophysical properties and microfilament assembly in neu- trophils: modulation by cyclic AMP. J. Cell Biol. 114:1179-1190.

29. Quilliam, L.A., H. Mueller, B.P. Bohl, V. Prossnitz, L.A. Sklar, C.J. Der, and G.M. Bokoch. 1991. Rap1A is a substrate for cAMP-dependent protein kinase in human neutrophils. J. Immunol. 147:1628-1635.

30. Nielson, C.P., R.E. Vestal, R.J. Sturm, and P.R. Heasli. 1990. Effect of selective phosphodiesterase inhibitors on the polymorphonuclear leukocyte respiratory burst. J. Allergy Clin. Immunol. 86:801-808.

31. Barnes, P.J., and R.A. Pauwels. 1994. Theophylline in the management of asthma: time for reappraisal? Eur. Respir. J. 7:579-591.

32. Rossi, A.G., J.M. Cousin, I. Dransfield, M.F. Lawson, E.R. Chilvers, and C. Haslett. 1995. Agents that elevate cAMP inhibit human neutrophil apoptosis. Biochem. Biophys. Res. Commun. 217:892-899.

33. Yasui, K., A. Komiyama, T.F.P. Molski, and R.I. Sha'afi. 1994. Pentoxifylline and CD14 antibody additively inhibit priming of polymorphonuclear leukocytes for enhanced release of superoxide by lipopolysaccharide: possible mechanism of these actions. Infect. Immun. 62:922-927.

34. Belloc, F., C. Jaloustre, P. Dumain, F. Lacombe, M. Lenoble, and M.R. Boisseau. 1995. Effect of pentoxifylline on apoptosis of cultured cells. J. Cardiovasc. Pharmacol. 25(Suppl.):71-74.

35. Hockenbery, D., G. Nunez, C. Millman, R.D. Shreiber, and S.J. Korsmeyer. 1990. Bcl-2, an inner mitochondrial protein that blocks programmed cell death. Nature (Lond.). 348:334-336.

36. Mentz, F., M.D. Mossalayi, F. Ouaaz, S. Baudet, F. Issaly, S. Ktorza, M. Semichon, J.-L. Binet, and H. Merle-Beral. 1996. Theophylline synergizes with chlorambucil in inducing apoptosis of B-chronic lymphocytic leukemia cells. Blood. 88:2172-2182. 